\title{
MAP0004 provided consistent migraine pain relief even after repeated administration
}

\author{
S Kori, B Lu, E Connors', X Li, D Kellerman \\ From The European Headache and Migraine Trust International Congress \\ London, UK. 20-23 September 2012
}

Oral tablets are the predominant route of administration for the acute treatment of migraine. Gastric Stasis (GS) is commonly associated with migraine, and can significantly alter the rate of intestinal absorption of an oral tablet, leading to inconsistent response to the administered drug. The Tmax of a triptan administered as a tablet can vary from 25-120 min. MAP0004, an investigational drug that delivers dihydroergrotamine (DHE) systemically via the lungs using the TEMPO ${ }^{\circledR}$ inhaler, bypasses the gastrointestinal tract. Consequently, GS is likely to have no effect on the absorption of drug into the bloodstream. MAP0004 administration consistently achieves a DHE Tmax between 7-12 min. A consistent Tmax, however, does not necessarily represent a consistent clinical response. A retrospective analysis was undertaken to determine whether pain relief rates were consistent across the 1st, 5th, 15th and 25th headache treated with MAP0004.

A total of 153 subjects within the open label, long term safety study who had at least 25 qualifying migraines were analyzed. Pain relief at 2 hours was seen on an average of $54.1 \%$, and there was no significant difference when comparing subsequent migraines to the first qualifying migraine or comparing the 1st, 5th, 15th and 25th all together. Similarly, analysis of pain free values at 2 hours (average $=24 \%$ ), sustained pain relief from 2-24 hours (average $=38.4 \%$ ), and sustained pain free values from 2-24 hours (average $=16.7 \%$ ) were not statistically different from the first qualifying migraine or comparing the 1st, 5th, 15th and 25th all together. In this retrospective analysis, MAP0004 provided a consistent and similar response rate in treating an episodic migraine attack, whether it was the 1st, 5 th, 15 th or the 25 th headache treated.

Published: 21 February 2013
Reference

1. Aurora SK, Silberstein SD, Kori SH, et al: MAP0004, Orally Inhaled DHE: A Randomized, Controlled Study in the Acute Treatment of Migraine (301). Headache 2011, 51:507-517.

doi:10.1186/1129-2377-14-S1-P190

Cite this article as: Kori et al:: MAP0004 provided consistent migraine pain relief even after repeated administration. The Journal of Headache and Pain 2013 14(Suppl 1):P190.

Submit your manuscript to a SpringerOpen ${ }^{\odot}$ journal and benefit from:

- Convenient online submission

- Rigorous peer review

- Immediate publication on acceptance

- Open access: articles freely available online

- High visibility within the field

- Retaining the copyright to your article

Submit your next manuscript at $>$ springeropen.com 